\title{
A afetividade na relação professor-aluno e suas implicações na aprendizagem, em contexto universitário
}

\section{The affection in the teacher-student relationship and its implications on learning in the university context}

\author{
Renata da Silva Veras ${ }^{1}$ \\ Sandra Patrícia Ataíde Ferreira ${ }^{2}$
}

\begin{abstract}
RESUMO
O presente trabalho teve por objetivo investigar como a postura do professor, em sala de aula, tem implicações sobre a experiência de aprendizagem positiva de estudantes universitários, em uma turma do $1^{\circ}$ período e outra do $3^{\circ}$ período do curso de Graduação em Pedagogia, de uma universidade pública situada na cidade de Recife-PE. Para tanto, foram realizadas quatro observações em cada uma das turmas investigadas e entrevistas semiestruturadas com quatro professores e oito alunos, sendo quatro de cada turma. Foi realizada uma análise qualitativa e os dados foram sistematizados em dois temas, a saber: (i) Postura do professor em sala de aula e a experiência de aprendizagem do aluno; (ii) Aspectos positivos e negativos na relação afetiva entre professor-aluno em sala de aula. Os resultados apontaram que quando os professores e alunos contribuem para uma relação afetiva positiva, isso implica em uma experiência de aprendizagem favorável.

Palavras-chave: afetividade; professor-aluno universitários; ensino-aprendizagem.
\end{abstract}

\begin{abstract}
This study aimed at investigating how the stance of the teacher in the classroom implicates on a positive learning experience for students. This study was conducted in a Pedagogy Undergraduate Course with 1 st and 3rd period classes, at a public university located in the city of Recife-PE. Therefore, we made 4 observations in each of the classes investigated
\end{abstract}

1 Graduada em Pedagogia - Universidade Federal de Pernambuco - Brasil. E-mail: natadsv@gmail.com.

2 Doutora em Psicologia Cognitiva - Universidade Federal de Pernambuco - Brasil. E-mail: taanda@terra.com.br. 
and we also conducted semi-structured interviews with four teachers and eight students -four from each class. We performed a qualitative analysis and the data was organized into two themes, namely: (i) posture of the teacher in the classroom and learning experience for the student, (ii) positive and negative aspects in the affective relationship between teacher-student in classroom. The results showed that when teachers and students contribute to a positive affective relationship, it leads to a positive learning experience.

Keywords: affectivity; university professor-student; teaching-learning.

\section{A Afetividade na relação professor-aluno: uma perspectiva da Psicogênese da Pessoa Completa}

A tradicional valorização da dimensão cognitiva em detrimento da afetiva, na trajetória do pensamento e do conhecimento humano, e a visão dualista do homem enquanto corpo/mente, matéria/espírito, afeto/cognição têm dificultado a compreensão das relações entre ensino e aprendizagem e da própria totalidade do ser, limitando o processo de formação de estudantes de vários níveis de escolaridade.

Com base em uma perspectiva histórico-cultural, a teoria de Wallon destaca-se nos estudos sobre afetividade, afirmando em sua teoria da Psicogênese da Pessoa Completa, que a dimensão afetiva, ao longo de todo o desenvolvimento do indivíduo, tem um papel fundamental para a construção da pessoa e do conhecimento.

Segundo esse autor, o termo afetividade corresponde às primeiras expressões de sofrimento e de prazer que a criança experimenta, sendo essas manifestações de tonalidades afetivas ainda em estágio primitivo, ou seja, de base orgânica e têm por fundamento o tônus. Este, por sua vez, representa a base de onde sucedem as reações afetivas e mantém uma relação estreita com a afetividade durante o processo de desenvolvimento humano. Ao se desenvolver, a afetividade passa a ser fortemente influenciada pela ação do meio social. Tanto que este autor defende uma evolução progressiva da afetividade, cujas manifestações vão se distanciando da base orgânica, tornando-se cada vez mais relacionadas ao social. (WALLON, 1941/2007).

A afetividade também representa um conjunto funcional abrangente, incluindo sentimentos, emoção e paixão. Embora esses termos sejam, geralmente, confundidos, na teoria walloniana, existe distinção entre eles. A emoção, segundo Wallon (1941/2007), é a exteriorização da afetividade. Ela evolui como 
as demais manifestações, sob o impacto das condições sociais. É o primeiro recurso de ligação entre o orgânico e o social.

A emoção procede de variações do tônus visceral e muscular acompanhadas por prazer e desprazer por meio de alterações orgânicas, como a aceleração dos batimentos cardíacos; e as alterações físicas, expressas por meio de expressão facial, riso, lágrimas. A emoção tem o papel de unir os indivíduos entre si por suas reações mais orgânicas e mais íntimas, e essa confusão entre os sujeitos deve ter por consequência ulterior as oposições e os desdobramentos dos quais poderão gradualmente surgir as estruturas da consciência. Essa união interindividual inicia-se nos primeiros dias de vida e se fortalecem a partir das emoções, antes mesmo do raciocínio e da intenção, sendo o fenômeno da emoção, portanto, compreendido como a origem da consciência.

Já os sentimentos, segundo Wallon (1941/2007), não implicam reações instantâneas e diretas, como na emoção, e tendem a reprimi-las. Os sentimentos são manifestações mais evoluídas e aparecem mais tarde na criança quando se iniciam as representações. Com relação à paixão, esta surge com o progresso das representações mentais e pode ser intensa e profunda na criança. A paixão aparece com a capacidade de tornar a emoção silenciosa, ou seja, envolve o autocontrole do comportamento e, assim como os sentimentos, só aparece mais tarde, por volta dos três anos de idade, quando começam a atuar as representações.

Embora o desenvolvimento humano na teoria Walloniana seja descrito até a adolescência, Wallon (1986) afirma que esse desenvolvimento não termina nesse momento, pois "a constituição do "eu" é um processo que jamais se acaba: o outro interior, ou fantasma do outro, vai acompanhar o "eu" durante toda a vida". (NASCIMENTO, 2004 p. 56).

Como afirmam Mahoney e Almeida (2005), apesar desse movimento de incorporação e oposição de vários outros, mesmo após a adolescência, o adulto se reconhece como o mesmo e único ser. É capaz de afirmar com certa segurança: Eu sei quem sou. Ou seja, conhece melhor suas possibilidades, limitações, seus pontos fortes, suas motivações, seus valores e sentimentos, o que cria a possibilidade de escolhas mais adequadas nas diferentes situações de vida.

Portanto, podemos afirmar que a afetividade constitui um fator de grande importância no processo de desenvolvimento do indivíduo e na relação com o outro, pois é por meio desse outro que o sujeito poderá se delimitar como pessoa nesse processo em permanente construção. Nesse sentido, é essencial que o professor de Ensino Superior também esteja envolvido nesse processo, considerando a afetividade como parte do desenvolvimento, buscando a formação integral dos estudantes universitários e uma vivência positiva da aprendizagem.

Assim, é possível afirmar que caberá ao professor articular os aspectos afetivo e cognitivo, pois, como afirmam Leite e Tassoni (2006), em todas as prin- 
cipais decisões de ensino assumidas pelo professor, a afetividade está presente: na escolha dos objetivos de ensino, no ponto de partida do processo de ensinoaprendizagem, na organização dos conteúdos, nos processos e atividades de ensino e nos procedimentos de avaliação, constituindo-se como fator fundante das relações que se estabelecem entre os alunos e os conteúdos escolares ou acadêmicos, na mediação com o professor.

Além disso, será pelo conjunto das diversas formas de atuação do professor durante essas atividades pedagógicas, que ele vai qualificando a relação que se estabelece entre o aluno e os diversos objetos de conhecimento (TASSONI, 2006). Nesse sentido, é possível afirmar que para estabelecer uma relação afetiva é preciso que professores e estudantes estejam dispostos a esse mesmo objetivo, pois a postura que for tomada poderá influenciar na postura do outro, refletindo assim no processo ensino-aprendizagem. A importância da dimensão afetiva nesse processo, em contexto universitário, pode ser vislumbrada, por exemplo, nos estudos de Oliveira (2005) e Silva (2005), que investigaram a integração da afetividade na prática pedagógica.

Oliveira (2005) teve como objetivo contribuir para a construção de propostas pedagógicas que considerem a dimensão afetiva. Esse estudo contou com a participação de estudantes universitários de Licenciatura em Educação Física que atuam lecionando em um projeto de extensão universitária oferecido pela Instituição de Ensino Superior privada, situada na Grande São Paulo, que atende crianças e adolescentes. A pesquisa foi desenvolvida com base nos pressupostos metodológicos da pesquisa-ação e a partir de três diretrizes básicas: a) estudo e reflexão sobre a temática afetividade; b) expressão verbal e reflexão sobre afetividade dos professores e dos alunos; c) participação na construção de práticas pedagógicas que considerassem a dimensão afetiva. Os dados revelaram que os licenciandos passaram a apresentar maior atenção às manifestações afetivas dos seus alunos, passando a reconhecer a importância dessa dimensão e a envolverem-se na busca de caminhos para a consideração da afetividade em suas práticas pedagógicas.

Embora esse estudo leve em consideração as relações professor-aluno durante as atividades de ensino de Educação Física, ele se volta, especialmente, para a formação de professores que levem em conta a dimensão afetiva no planejamento de suas atividades pedagógicas. Apesar de envolver os alunos como participantes da pesquisa, não há ênfase na experiência de aprendizagem desses alunos que vivenciam uma relação com seus professores.

Já a pesquisa desenvolvida por Silva (2005), teve como objetivo verificar se a mobilização corporal gerava mudanças afetivas e cognitivas no indivíduo, influenciando na relação professor-aluno e no processo ensino-aprendizagem. Essa pesquisa foi realizada no Ensino Superior, no curso de Medicina Veterinária, de 
uma instituição situada no interior da cidade do estado de São Paulo e contou com a participação de professores e alunos, tendo como base a teoria do desenvolvimento de Henri Wallon e os princípios da Bioenergética. Os resultados, após a análise das entrevistas e dos relatos dos professores e alunos, demonstraram que os exercícios da Bioenergética refletiram especialmente nas alterações percebidas em si mesmas, nos aspectos afetivos, corporais e cognitivos; nas relações interpessoais, principalmente com colegas, alunos e professores; nas relações com os animais e na relação com os estudos e também, no caso dos professores, na preparação das aulas. Portanto, esse estudo permitiu que o contato e a expressão dos sentimentos e emoções fossem viabilizados por meio de movimentos que estimulavam as sensibilidades interoceptivas, articulares, proprioceptivas e exteroceptivas, favorecendo a expressão da emoção e a mudança afetiva e cognitiva; ao mesmo tempo em que comprova pautado na perspectiva walloniana, as estreitas relações entre movimento, afetividade e cognição. No entanto, além de se utilizar de um recurso alheio às atividades à prática pedagógica, como é o caso dos exercícios de Bioenergética, este estudo não tem como foco a sala de aula, nem privilegia a relação professor e aluno, visto que esses atores são considerados separadamente. Em síntese, esses estudos buscaram, a partir da psicologia, contribuir para a lacuna ainda existente no processo de ensino-aprendizagem que tem limitado a formação do aluno, valorizando a cognição em detrimento das dimensões afetiva e motora do desenvolvimento humano. Porém, não exploraram a relação de afetividade entre professor e aluno de forma integrada, no ambiente de sala de aula do Ensino Superior e nem suas experiências de aprendizagem. Nesse sentido, nesse artigo analisa-se a afetividade na relação entre professores e alunos no espaço acadêmico e suas implicações na aprendizagem, buscando contribuir para a reflexão dos professores e alunos sobre a importância de conquistar um relacionamento interpessoal saudável para que possam vivenciar positivamente a aprendizagem dos conteúdos acadêmicos ao longo da graduação. Assim, tem-se o objetivo de investigar como a postura do professor, em sala de aula, tem implicações sobre a experiência de aprendizagem positiva de estudantes universitários

\section{Procedimentos e ferramentas de construção dos dados}

Para o desenvolvimento dessa pesquisa, foi realizada uma abordagem qualitativa, uma vez que, ela oferece os dados básicos para o desenvolvimento e a compreensão das relações entre os atores sociais e sua situação, como também uma compreensão detalhada das crenças, atitudes, valores e motivações em 
relação aos comportamentos das pessoas, em contextos específicos. (BAUER; GASKELL, 2007). Então, para entender as posturas de professores no contexto de sala de aula, foram utilizadas nesta pesquisa a observação e a entrevista como técnica de coleta de dados.

A opção pela observação na sala de aula teve como objetivo perceber como se dá a afetividade na relação professor-aluno; contribuindo, neste caso, para a observação de atitudes de professores e alunos em situações de ensino e aprendizagem. Já as entrevistas, tiveram o objetivo de identificar as experiências afetivas vivenciadas por esses atores, nas suas relações em sala de aula.

As observações foram realizadas com professores permanentes lecionando a mais de dois anos em uma universidade pública situada na cidade de Recife-PE; e selecionados aleatoriamente. Foram realizadas oito observações, sendo quatro em cada uma das turmas investigadas: uma do primeiro período (Turma A: 60 alunos aproximadamente) e outra, do terceiro (Turma B: 45 alunos em média), uma vez que dois dos professores que participaram da pesquisa estavam lecionando na turma do primeiro, e os outros dois na turma do terceiro período.

As observações tiveram a duração de duas semanas consecutivas, com o tempo de cada observação variando de 1 hora e 40 minutos a 1 hora e 50 minutos, de acordo com a atividade realizada em sala de aula pelo professor. $\mathrm{O}$ foco das observações foram as atitudes de professores e alunos em situações de ensino e aprendizagem. Para a realização desse procedimento, foram utilizados como recursos materiais o lápis e papel. Os registros das observações eram realizados durante e após as sessões e separados em protocolos individuais.

Após as sessões de observação, foram realizadas entrevistas individuais com os quatro professores e mais oito alunos, quatro de cada turma observada, a partir de dois diferentes roteiros semiestruturados, sendo um para cada um desses dois grupos de participantes. Em ambos os roteiros, foram abordados aspectos referentes à importância do processo de ensino e aprendizagem, e da relação professor-aluno. Para o registro dessa situação, foi utilizado um MP3. As entrevistas aconteceram sempre após as observações a fim de evitar que seu conteúdo influenciasse na atuação dos professores e alunos no momento das observações.Posteriormente, com os dados obtidos nas observações e nas entrevistas, foram realizadas as transcrições em protocolos individuais e analisados de forma qualitativa, a partir da descrição-interpretativa das observações, e da organização e interpretação das informações coletadas nas entrevistas semiestruturadas. A partir do intercruzamento das várias informações coletadas nas observações e entrevistas foi possível elaborar dois temas de análise, a saber: (i) Postura do professor em sala de aula e a experiência de aprendizagem do aluno; (ii) Aspectos positivos e negativos na relação afetiva entre professoraluno em sala de aula. 


\section{Postura do professor em sala de aula e a experiência de aprendizagem do aluno}

Ao analisarmos a postura do professor em sala de aula e a experiência de aprendizagem do aluno, entendemos, nesta pesquisa, que o professor exerce um importante papel de mediação, que poderá favorecer ou não à construção do conhecimento pelo aluno.

Essa postura do professor na sala de aula parece afetar diretamente na experiência de aprendizagem do aluno; seja de maneira positiva ou negativa. Como lembra Leite (2006, p. 26), “A natureza da experiência afetiva (se prazerosa ou aversiva), nos seus extremos depende da qualidade da mediação vivenciada pelo sujeito, na relação com o objeto.", sendo esta favorecida pela história de relação do professor com o seu objeto de ensino e pelo investimento que realiza na mediação entre aluno e este objeto através da postura que assume em sala de aula.

No que se refere a esta postura do professor em sala de aula, percebeuse nas sessões de observação, que os professores investigados, de modo geral, procuravam criar um clima de respeito entre eles e os alunos; demonstrando interesse com suas aprendizagens e buscando ouvi-los, de modo a valorizar os conhecimentos e vivências trazidas por eles, e também os mobilizando para as leituras dos textos sugeridos.

A Professora 1, que lecionava na turma A, por exemplo, não impõe decisões na sala de aula e se mostrava sempre preocupada em saber se os alunos compreendiam o conteúdo, buscando planejar a disciplina de modo a atender às necessidades e favorecer o avanço dos alunos. Sobre isso diz:

Às vezes eu acho que dou liberdade demais, mas com essa turma em particular é uma construção de trabalho, mais leve, gratificante sem aquela coisa de estar muito distante porque a própria postura em sala contribui para que o trabalho em si seja com mais facilidade (Professora 1 - Turma A)

Essa postura da professora é observada pelos alunos da turma A como algo positivo e importante; já que consideram que ela tem o interesse em ouvir a opinião deles sobre o conteúdo e a dinâmica das aulas, sendo estas atitudes relevantes para favorecer-lhes uma experiência positiva na aprendizagem, como revela uma das alunas: 
Eu gosto (da professora) porque ela trabalha de maneira bem moderna [...] não é aquela disciplina antiga [...] Eu acho que ela trabalha de maneira bem variada. Trabalho de grupo, apresentou documentário [...] ela é bem dinâmica. Então, eu acho que facilita, a aula não fica uma coisa chata e a gente percebe que ela tá sempre se preocupando dizendo 'e ai vocês estão gostando do filme, tão gostando das aulas? (sexo feminino, $1^{\circ}$ período)

Percebe-se na fala da aluna que, a preocupação da professora com o planejamento da disciplina, de modo que despertasse o interesse da turma; foi possível através da variabilidade de recursos que foram utilizados durante a aula, como, por exemplo, filmes e documentários, e dessa forma, como afirma Falcin (2006), o professor também contribui para o estabelecimento de uma relação positiva entre sujeito e o objeto de conhecimento.

Já o Professor 2, que leciona na turma A, também tem a preocupação com o aprendizado do aluno e com a sua compreensão acerca dos temas discutidos, além de se mostrar atencioso e bem humorado. Ao falar de sua postura em sala de aula, diz:

[...] gostaria de ser mais sistemático, mais rigoroso no tratamento de alguns assuntos, e então eu acho que eu me guardo muito, às vezes, eu consigo me policiar sobre isso e voltar, e outras vezes não, por causa disso ai, uma falta de sistemática e também o seguinte: considere uma aula é de duas horas. É muito tempo. Essa aula você tem que ter momentos de descontração e sobre as últimas aulas que você observou foi conceitual, pesada, é uma seqüencia de conceitos e que imagine duas horas daquilo, e a galera fica.... E tem que ter atenção pra focar o tempo todo [...] (Professor 2 - Turma A)

Embora o professor entenda que precise ser mais sistemático durante as aulas, esse aspecto não foi apontado pelos alunos. Pelo contrário, estes apenas relataram o interesse pelo conteúdo da disciplina, como diz um aluno da turma A: "Eu gosto da disciplina dele. Porque acho o assunto interessante, retrata o dia a dia da gente." (sexo masculino $1^{\circ}$ período) 
A partir da fala do aluno, percebe-se que, ao trabalhar com temas que tem relação com a vida do estudante e com as práticas sociais do ambiente em que vive; o Professor 2 marca afetivamente a mediação estabelecida entre ele, o objeto de conhecimento e o aluno e, consequentemente, promove relações afetivas positivas com o objeto de conhecimento (LEITE, 2006).

Com relação à Professora 3 , que leciona na turma $\mathrm{B}$, esta preza por chegar sempre no horário, busca ser parceira dos alunos, interagindo durante as aulas e demonstrando ser atenciosa com eles. Ao final das suas aulas, como foi observado, conversa com a turma para saber o que facilitou e o que dificultou na discussão daquela aula. Também é exigente consigo mesma e na cobrança das atividades sugeridas. Como diz:

\begin{abstract}
[...] eu acho que eu procuro ter uma postura de diálogo, de abertura para o diálogo e tento chegar até o estudante, estabelecer parcerias e cobro muito. É uma coisa que reconheço, mas é exigente, mas tem uma coisa... Sou exigente comigo mesma, de estabelecer regras, organizar o cronograma, mas cobro muito, sou metódica [...] Acho que a minha postura é de provocação, de parceria e muito respeito, pelo menos é o que pretendo. (Professora 3 - Turma B)
\end{abstract}

A partir da fala da professora, podemos observar que a sua prática pedagógica prima pela corresponsabilização, uma vez que, ao mesmo tempo em que é exigente com o estabelecimento das regras, horários e com a organização do planejamento; também envolve os alunos no processo de ensino e aprendizagem a partir do diálogo e da negociação. Essa postura da professora é apontada pelos alunos como positiva, como relata um deles: “[...] ela está sempre procurando tirar dúvidas dos alunos, atenciosa, a gente percebe a preocupação dela com a nossa aprendizagem, ela está sempre ali, em cima." (sexo feminino, $3^{\circ}$ período)

Os alunos ainda afirmam que a forma de avaliação dos exercícios propostos pela professora também influencia na sua experiência de aprendizagem. Um dos estudantes da turma B comenta que: “[...] Ela entrega a nota, chega para o grupo e explica, tem todo um acompanhamento, a gente recebe um retorno do nosso desempenho e a gente vê que está crescendo". (sexo feminino, $3^{\circ}$ período)

Podemos observar com relação às atividades solicitadas, que a professora não tem o objetivo de estabelecer apenas uma nota, mas demonstra todo um cuidado para que o aluno tenha a percepção de seus avanços e dificuldades. 
Segundo Leite (2006), esse tipo de atuação pedagógica favorece não apenas o avanço cognitivo dos alunos, mas propicia condições afetivas positivas entre o aluno e os conteúdos acadêmicos.

Com relação à postura do Professor 4, que leciona na turma $\mathrm{B}$, este é um professor carismático, que busca de maneira bem humorada expor o conteúdo, fazendo inclusive desenhos no quadro, no momento da explicação, com o objetivo de descontrair a turma.

Sobre a sua postura diz:

Eu acho que a minha postura é informal demais, eu acho que eu deveria ser um pouco mais formal, não sei, às vezes eu falo uns exemplos que não tem nada haver. Ao mesmo tempo em que eu peço para fazer silêncio, né, ai eu falo vamos escutar o outro tentando criar um pouco de controle sobre o grupo que talvez esse controle não seja de..(Entrevistadora: de grosseria ou autoritária?) Pode ser. Eu acho que autoritarismo, porque sempre permeia a relação pedagógica por mais que você não queira, você é sempre autoritário, por exemplo [...] a gente não pode fugir muito do que o departamento e o currículo de pedagogia têm aprovado [...] ai a gente tenta dai construir outros aspectos negociáveis. (Professor 4 - Turma B)

A partir da fala do professor podemos perceber que há busca de um clima saudável no qual os alunos possam se sentir à vontade para fazer perguntas, sem sentirem medo de participar durante as aulas, o que contribui para uma experiência de aprendizagem positiva, já que os alunos demonstram gostar do fato de poderem participar ativamente, manifestando suas dúvidas e pontos de vistas. Como diz um dos alunos:

Eu acho que o professor tem que ser aberto, tem que estar apto pra ouvir o aluno, pra fazer críticas quando necessário. Eu acho que a relação tem que ser muito aberta pra ter aquela socialização. Quando ele interage, é aberto, o conhecimento passa melhor pra gente. (Entrevistadora: você acha que a postura do professor (nome do professor) em sala de aula corresponde ao que você falou?) Corresponde sim. (sexo feminino, $3^{\circ}$ período) 
Neste caso, a postura de diálogo do professor com os alunos corresponde a um aspecto essencial nessa relação, pois, como afirma Wallon (1986 citado em NASCIMENTO, 2004), é pelo diálogo que o sujeito constrói sua inteligência; ao ser ouvido e refletir sobre a fala do outro, tem a possibilidade de desenvolvimento, em um processo de permanente construção, em que modifica e é modificado pelo outro.

Em resumo, pode-se afirmar que as decisões pedagógicas assumidas pelos docentes marcam efetivamente as condições de aprendizagem do aluno em sala de aula, seja de maneira positiva, como os dados dessa pesquisa demonstram, ou negativamente.

\section{Aspectos positivos e negativos na relação afetiva entre professor-aluno em sala de aula}

Estabelecer uma relação de afetividade positiva entre professor e aluno é um aspecto importante que deve estar presente no contexto da sala de aula, uma vez que, como diz Wallon (1986 citado em NASCIMENTO, 2004), as dimensões cognitivas e afetivas perpassam-se e influenciam de forma inseparável toda e qualquer atividade humana.

Tomando por base essas noções walonianas, percebeu-se que, de modo geral, nas turmas A e B, as relações entre professor-aluno são marcadas por uma afetividade positiva, ou seja, por sentimentos de prazer, de satisfação e bem-estar. Essas relações não são apenas vivenciadas tête-à-tête com o aluno, mas se mostram a partir das decisões que o professor assume antes mesmo de entrar em sala de aula, como é o caso, por exemplo, da elaboração do planejamento da disciplina (LEITE, 2006).

Percebeu-se que o diálogo e a proximidade com os alunos, foram aspectos positivos ressaltados pelos professores 1 e 2 que lecionam na turma A e pela Professora 3 que leciona na turma B. Isto é o que pode ser verificado nos seguintes relatos:

Não sei... Bem, pelo menos eu tento ter uma relação bem próxima. Não tem aquela coisa de estar no pedestal e o aluno embaixo, a gente, lógico, tem o domínio do conteúdo, é responsável por uma disciplina, mas não faço essa barreira com eles, e isso acredito que seja uma relação boa, positiva. (Professora 1 - Turma A) 
[...] eu acho que eu me aproximo muito dos alunos. Tenho certo cuidado com o aprendizado deles eu tenho essa relação de amizade, é... de criar um vinculo de amizade, [...] (Professor 2 - Turma A)

Eu acho que é uma relação de parceria mesmo, e tem uma coisa muito importante, é uma relação de chegar assim pra mim e dizer olha (nome da professora) eu gostei disso porque... Ou eu não gostei disso. É uma relação transparente, muito tranqüila e talvez porque não se deixa as coisas tomarem uma outra dimensão... No momento que, eu estou constantemente avaliando esse trabalho, tento não deixar as coisas pra depois [...] (Professora 3 - Turma B)

Embora afirmem estabelecer com o aluno uma relação baseada no diálogo e na amizade, esses professores têm consciência da autoridade que exercem nessas interações, já que existe uma "superioridade hierárquica de saberes" e uma proximidade com o objeto institucional (GROPPA AQUINO, 1998). Também se percebe que para se construir um trabalho mais prazeroso na sala de aula, o professor precisa ouvir, discutir e refletir junto com o aluno a melhor forma de conduzir esse trabalho, uma vez que o processo educativo é essencialmente interativo; e efetivado por meio das relações entre professor, aluno e objeto de conhecimento. Além disso, o fato do professor buscar estabelecer esse contato com o aluno também reflete nessa relação, como relatam os alunos da turma $\mathrm{A}$ sobre a Professora 1 e o Professor 2:

[...] todo mundo gosta da aula dela, todo mundo procura fazer os exercícios que ela manda... Pede né? (sexo masculino $1^{\circ}$ período)

Eu acho uma relação muito boa, assim eu percebo que a turma se sente a vontade na aula dele, entregam os relatórios que ele pede porque a gente tem que entregar esses relatórios sobre os textos, então o pessoal sempre faz. (sexo feminino, $1^{\circ}$ período) 
Portanto, o fato desses professores estarem sempre dispostos à atender os alunos e tirar as suas dúvidas na sala de aula; faz com que eles busquem contribuir com esta relação positiva, dando um retorno aos professores a partir do cumprimento das atividades sugeridas, o que, por sua vez, possibilita uma experiência prazerosa na aprendizagem.

No que se referem aos aspectos negativos vivenciados nas relações entre os professores e alunos das turmas investigadas, o Professor 2 ressalta a pouca participação dos estudantes durante as aulas e o fraco comprometimento com a leitura dos textos sugeridos. Sobre isso diz:

[...] lê eles leem, meio na marra, mas lê, agora se vocênão ficar ali olhando os textos... pode ser que só a metade vai ler. (Entrevistadora: eles participam das aulas?) Essa turma eu acho que o pessoal participa pouco, porque eu não tenho provocado a participação, eu acredito que a participação não é uma coisa que venha espontaneamente, em algumas turmas pode até dar espontaneamente, mas geralmente não, você tem que provocar [...] (Professor 2 -Turma A)

Esse chamado à participação parece ser algo valorizado pelo aluno, podendo a falta de estratégia por parte do professor para provocar a sua atuação na sala de aula, mostrar-se como um aspecto negativo no processo de ensino e aprendizagem. Sobre isso, uma das alunas da turma A, ao comentar sobre a postura do Professor 2, diz:

Só acho que falta ele incentivar mais o pessoal a participar, falta ele incentivar mais todo mundo a ler. (Entrevistadora: Mas o professor não abre espaço para vocês participarem?) É... ele pergunta se alguém quer falar, mas é aquela coisa, como vai perguntar se não sabe bem o assunto. (Entrevistadora: Mas o problema seria apenas do professor?) Não, dos alunos. (sexo feminino, $1^{\circ}$ período)

Nesse caso, para que os alunos possam participar ativamente na sala de aula, faz-se necessária uma ação mais direta do professor para promover essa participação, sendo essa condição essencial de um ambiente favorável à apren- 
dizagem do aluno. Quanto à relação da Professora 3 com os alunos da turma $\mathrm{B}$, uma das alunas afirma que

É ótima. Ela interage muito bem com os alunos, ela atrai mesmo, tem uma receptividade, os alunos gostam dela e quando ela vê que alguém está calado, ela chama logo a atenção, pergunta alguma coisa. Ela está sempre interagindo. (sexo feminino, $3^{\circ}$ período)

Essa professora constantemente provoca a participação da turma, buscando sempre incentivá-los, e como já sabe o nome de todos os alunos, durante a aula, faz perguntas não só para o grande grupo, mas diretamente a cada um deles. $\mathrm{O}$ fato de conhecer e chamar cada aluno pelo nome próprio, valorizando a identidade de cada um, foi apontado pelos alunos como algo positivo, como diz uma aluna da turma B: "Eu sinto que (nome da professora) puxa muito, sabe? Ela sabe o nome da gente né, ai incentiva a gente a participar." (sexo feminino, $3^{\circ}$ período)

Outro aspecto interessante a enfatizar sobre a relação professor-aluno, diz respeito ao relato do Professor 4, da turma B. Sobre isso diz:

Primeiro queria dizer que cada grupo é um grupo diferente, $e$ assim, ao longo da minha experiência como professor alguns grupos são mais resistentes... (Entrevistadora: e com essa turma?) Eu estou com um grupo interessante, interessado e interessante porque é, mesmo assim reclamando um pouco dos textos, de maneira geral, eles são bem interativos, assim, críticos também. (Professor 4 - Turma B)

Essa demonstração de interesse dos alunos da turma B quanto ao objeto de conhecimento, através da realização dos trabalhos sugeridos, e por meio da participação durante as aulas, parece ter implicações positivas na relação do professor com a disciplina que ministra; o que, por sua vez, reverte em uma relação positiva entre professor-aluno, como aponta um aluno da turma B: " $\mathrm{Eu}$ acho ótima a relação. Porque o professor é bem aberto, é divertido e assim... ele é descontraído, então, a sala fica tranquila, eu acho a relação muito boa". (sexo feminino, $3^{\circ}$ período) 
Enfim, é possível afirmar que, quando o professor provoca a participação dos alunos através do diálogo ou possibilita que eles se sintam à vontade na sala de aula, a relação professor-aluno é favorecida e, consequentemente, a construção de conhecimento. Afinal, ao permitir que falem, o professor favorece o confronto de pontos de vista, o possível surgimento do conflito cognitivo e sua provável superação. Além disso, a afetividade que se manifesta nessa relação entre professor-aluno, constitui-se elemento inseparável do processo de aprendizagem e a própria qualidade da interação pedagógica vai conferir um sentido afetivo para o objeto de conhecimento (TASSONI, 2000); uma vez que entre professor-aluno, há uma relação de pessoa para pessoa e, portanto, o afeto está presente. (ALMEIDA, 1999).

\section{Considerações Finais}

A sala de aula é um espaço onde professores e alunos convivem diariamente, onde o sujeito aprende e se envolve ativamente no processo de ensinoaprendizagem por meio das interações sociais que mantém com os outros e com os objetos do conhecimento. No entanto, o sucesso dessa construção vai depender basicamente da qualidade dessas relações. (LEITE, 2006).

A partir das observações e entrevistas realizadas neste estudo, foi possível perceber a presença da afetividade positiva tanto nas relações entre professor e aluno, como na prática pedagógica assumida pelos docentes, expressa nas seguintes posturas: no planejamento da disciplina, levando em consideração os limites e possibilidades dos alunos; na escolha dos procedimentos de ensino, ao buscar a melhor forma de expor o conteúdo; na avaliação, acompanhando o aluno e fazendo o feedback no decorrer de todo processo de ensino e aprendizagem; no compartilhamento das responsabilidades que as situações pedagógicas exigem.

Os dados deste estudo revelaram que a postura tomada pelo professor na sala de aula favoreceu o estabelecimento de uma relação positiva entre o sujeito e os conteúdos acadêmicos, uma vez que, foi possível observar na fala deles, que a atuação dos professores despertou o seu interesse no aprendizado do objeto de conhecimento, fazendo com que buscassem dar um retorno aos professores através do cumprimento das atividades solicitadas e da participação efetiva nas aulas. Também o fato de vivenciarem uma relação positiva com o professor através do diálogo e da proximidade, contribuiu para um ambiente de ensino e aprendizagem prazeroso. 
Nesse sentido, como defende a teoria psicogenética de Wallon (1941/2007), a dimensão afetiva não pode ser considerada separada da inteligência. Segundo esta perspectiva teórica, a evolução da afetividade depende das construções realizadas no plano da inteligência, assim como, a evolução da inteligência depende das construções afetivas. Assim, a dimensão afetiva está sempre presente afetando o processo de ensino-aprendizagem e sendo este sempre afetado por ela. (OLIVEIRA, 2005).

Desta forma, podemos afirmar, a partir do que foi exposto até aqui, que tanto os professores quanto os alunos admitem que ao adotarem sentimentos de acolhimento e atenção no processo ensino-aprendizagem, bem como ao tomar decisões comprometidas com o desenvolvimento de todos, favorecendo a compreensão, aceitação e valorização do outro; possibilitam a promoção de uma experiência positiva da aprendizagem. Estes resultados estão de acordo com os achados dos estudos de Silva (2005) e Oliveira (2005), realizados em contextos universitários, pelo menos, no que diz respeito aos efeitos positivos que a consideração da dimensão afetiva provoca nas atividades pedagógicas e, consequentemente, nas relações estabelecidas entre professor, aluno e objeto de conhecimento, em sala de aula.

Portanto, entendemos, através desse estudo, que a prática pedagógica quando pautada em uma relação de corresponsabilização, favorece a participação ativa de todos os envolvidos no processo de ensino-aprendizagem em situação universitária, possibilitando aos estudantes experiências de sucesso na sua aprendizagem dos conteúdos acadêmicos.

\section{REFERÊNCIAS}

ALMEIDA, A. R. S. A emoção na sala de aula. Campinas: Papirus, 1999. p. 50 .

BAUER, Martin W.; GASKELL, George. Pesquisa Qualitativa com texto, Imagem e som: um manual prático. Tradução de: Pedrinho A. Guareschi. 6 ed. Petrópolis, RJ: Vozes, 2007. p. 64-88.

FALCIN, D. C. Afetividade e condições de ensino: histórias de professores inesquecíveis. In: LEITE, S. A. S (Org.). Afetividade e práticas pedagógicas. São Paulo: Casa do Psicólogo, 2006.

GROPPA, Aquino Júlio. A violência escolar e a crise da autoridade docente. Cad. CEDES, v.19, n. 47, p. 7-19, dez. 1998. 
LEITE, Sérgio Antônio da Silva. Afetividade e práticas pedagógicas. São Paulo: Casa do psicólogo, 2006. p. 15-95.

LEITE, Sérgio Antônio da Silva. Dimensões afetivas na relação professor-aluno In: FALCI, Daniela C. Afetividade e condições de ensino: histórias de professores inesquecíveis. São Paulo: Casa do psicólogo, 2006. p. 76-95.

LEITE, Sérgio Antônio da Silva. Dimensões afetivas na relação professoraluno In: TASSONI, Elvira Cristina Martins. A afetividade em sala de aula: as condições de ensino e a mediação do professor. São Paulo: Casa do psicólogo, 2006. p. 47-74.

MAHONEY, A. A.; ALMEIDA. L. R. Afetividade e processo ensino-aprendizagem: contribuições de Henri Wallon. Psi. da Ed., São Paulo, 20, p. 11-30, $1^{\circ}$ sem. de 2005 .

NASCIMENTO, Maria Letícia B. P. A criança concreta, completa e contextualizada: a psicologia de Henri Wallon. In: . CARRARA, Kester. Introdução à psicologia da educação: seis abordagens. São Paulo: Avercamp, 2004.

OLIVEIRA, Greice Kelly. Afetividade e prática pedagógica: Uma proposta desenvolvida em um curso de formação de professores de educação física. Tese (Doutorado) - PUC, São Paulo, 2005.

SILVA, Angélica do Rocio Carvalho. Sentimentos e emoções: um estudo com professores e alunos de medicina veterinária.Tese (Doutorado) - PUC, São Paulo, 2005.

TASSONI, E. C. M. Afetividade e aprendizagem: A relação professor e aluno. Anuário 2000. GT Psicologia da educação, Anped, setembro, 2000.

WALLON, H. A evolução psicológica da criança. São Paulo: Martins Fontes, 2007.

WALlON, H. As origens do pensamento da criança. São Paulo: Manole, 1986.

Texto recebido em 27 de fevereiro de 2009.

Texto aprovado em 16 de março de 2009. 